\title{
Sujeitos da antítese e os desafios da práxis da Reforma Sanitária Brasileira
}

\author{
Subjects of the antithesis and the challenges of the praxis of the \\ Brazilian Health Reform
}

Jairnilson Silva Paim ${ }^{1}$

RESUMO O conceito de revolução passiva tem sido utilizado como recurso para a análise da Reforma Sanitária Brasileira (RSB). Pode ser considerado, também, como um critério para que sujeitos desequilibrem o binômio conservação-mudança. $\mathrm{O}$ artigo tem como objetivo discutir os conceitos de sujeitos da práxis e de sujeitos da antítese para a análise da RSB. Ao considerar a conjuntura atual, o estudo procura caracterizar distintos sujeitos que transitam por projetos em disputa na saúde. Conclui chamando atenção para o fato de a RSB se apresentar até o presente como uma reforma parcial, o que não significa anular as possibilidades de os sujeitos da antítese conduzirem o seu processo para uma reforma mais ampla.

PALAVRAS-CHAVE Política de saúde. Sistema Único de Saúde. Revolução passiva. Movimento da Reforma Sanitária. Reforma dos serviços de saúde.

ABSTRACT The concept of passive revolution has been used as a resource for the analysis of the Brazilian Health Reform (RSB). It can be considered, as well, as a criterion for subjects to unbalance the conservation-change binomial. The article aims to discuss the concepts of praxis subjects and subjects of the antithesis for the analysis of the RSB. When considering the present conjuncture, the study seeks to characterize different subjects that transit through projects in dispute in health. It concludes by drawing attention to the fact that the RSB presents itself to the present as a partial reform, which does not mean to nullify the possibilities of the subjects of the antithesis to lead their process towards a wider reform.

KEYWORDS Health policy. Unified Health System. Passive revolution. Health Reform Movement. Health care reform. 


\section{Introdução}

O uso do conceito de revolução passiva como ferramenta de análise, interpretação e explicação para o desenvolvimento da Reforma Sanitária Brasileira (RSB) reitera a necessidade de estudar e pensar o Brasil, sua sociedade, seu Estado e sua cultura (IANNI, 2004) com o intuito de analisar os limites e as possibilidades desse 'projeto e processo' (PAIM, 2008B).

Esse recurso heurístico não deve ser visto como justificativa, pretexto ou desculpa para o fato de a RSB ser considerada uma 'promessa não cumprida'. Nem mesmo como espécie de racionalização para os 'filtros' pelos quais passou ou para outros possíveis históricos que não se viabilizaram (SCHRAIBER, 2008). Assim, o conceito de 'revolução passiva' não deve ser visto como forma de dourar o conformismo de muitos nem a resignação de outros. Ao contrário, tendo em conta que as mudanças sociais verificadas na História do Brasil não são as do tipo jacobino, a compreensão da dialética da mudança-conservação ou da revolução-restauração permite orientar a ação de sujeitos no sentido de tornar menos conservadora a resultante desse processo.

O 'dilema reformista', já apontado desde o início do processo da RSB (TEIXEIRA, 1989) e retomado em estudos mais recentes (DANTAS, 2014; SILVA, 2016), requer sujeitos sociais que incidam sobre certos componentes da 'revolução passiva' brasileira. Nesse sentido, a 'revolução passiva' representa um critério para que tais sujeitos desequilibrem o binômio da conservação-mudança em favor das forças progressistas e contribuam para mudar a direção do 'transformismo'. Esses 'portadores da antítese' (VIANNA, 2004) poderiam ser identificados, ainda que em estado prático, em novas conjunturas, ou constituídos de forma deliberada, enquanto 'sujeitos da antítese'. Nesse sentido, o presente artigo tem como objetivo discutir os conceitos de 'sujeitos da práxis' e de 'sujeitos da antítese' para a análise de conjunturas e práxis da RSB.

\section{Sujeitos da práxis e sujeitos da antítese}

A constituição de um sujeito social supõe a superação da sua condição de indivíduo, quando incorpora uma ideologia, e a possibilidade de se tornar um ator social na medida em que seja capaz de incluir temas na agenda do Estado (TESTA, 1995). A sua intencionalidade, analisando concretamente as circunstâncias, poderia aguçar a consciência crítica, estimular a mobilização, perseguir a organização e buscar a efetividade da intervenção enquanto sujeito transformador (TESTA, 2007).

Toda práxis supõe a existência de um sujeito que se contrapõe ao objeto e toma iniciativa (sujeito da práxis), mas que pode, também, sujeitar-se, tal como sugere a sua etimologia, que vem de subjectus (sujeitado). Assim, não existe práxis sem sujeito. E se a práxis é práxis do sujeito, cabe em cada situação concreta identificar os sujeitos da práxis. Além disso, considera-se a possibilidade de que, em circunstâncias especiais a serem investigadas concretamente, alguns desses sujeitos da práxis possam se transformar em sujeitos da antítese, desenvolvendo uma práxis na perspectiva dialética (GRAMSCI, 1966) e intervindo, concretamente, sobre a realidade.

A elaboração teórica (ALTHUSSER, 1978) sobre o sujeito da antítese inspira-se na noção de 'portadores da antítese' (VIANNA, 2004). Nesse sentido, é fundamental considerar os três momentos do processo dialético - tese, antítese e síntese:

O primeiro momento desse processo - a tese -, apresenta-se como uma identidade. [...] O positivo só o é aparentemente; pois em verdade, a identidade inicial contém o negativo. [...] Daqui nasce um movimento: a contra-dicção, ou o não-idêntico, o diferente do idêntico, adquire certa autonomia. [...] A dicção se transforma pois em contra-dicção, a tese se torna antítese. O segundo momento do processo constitui uma explicitação do negativo [...]. No momento em que surge a determinação 
da antítese estabelece-se o movimento da contradição, que é a alma de toda a dialética, ou da verdade entendida como processo. [...]. A contradição, portanto, dá lugar a um novo momento que é a síntese, e que faz da verdade o resultado de um processo do mesmo modo como a antítese explicita a tese, a síntese desdobra a antítese, em busca de uma identidade superior. (BORNHEIM, 1983, P. 49-51).

Concedendo-se à antítese o caráter de negação da tese, representada pela manutenção do status quo, o conceito de sujeito da antítese deve ser investigado para além do produto de um trabalho teórico, propósito do presente texto, e, sim, a partir da práxis. Mas no momento inicial de elaboração teórica, seria necessário conceituar sujeito da antítese. Em outras oportunidades, caberia investigar, concretamente, conjunturas no sentido de averiguar a existência de sujeitos da antítese na realidade social. Contudo, uma advertência se faz necessária:

A dialética não encontra seu ponto de partida na subjetividade do sujeito, qualquer que seja a interpretação que se lhe empreste. A dialética se tornou incompatível com o subjetivismo, em todas as suas modalidades. A razão disso é simples: a dialética não pode sobrepor-se à realidade. (BORNHEIM, 1983, P. 177).

Desse modo, a análise de conjunturas pode ser uma via de superar o subjetivismo, examinando escrupulosamente a realidade. O mapeamento dos sujeitos de práxis e a identificação de sujeitos da antítese em situações concretas comporiam um processo de investigação e, simultaneamente, alimentariam o pensamento estratégico a orientar a intervenção.

\section{Os sujeitos da antítese e a 'grande política' da RSB}

Na RSB, o sujeito da antítese merece ser pensado na perspectiva da 'grande política', ainda que possam ser identificados atores que, exercendo a 'pequena política', fazem-no de modo mais amplo na construção e na defesa de um dado projeto durante os diversos 'momentos parciais':

Na história real, a antítese tende a destruir a tese, a síntese será uma superação, mas sem que se possa estabelecer a priori o que será 'conservado' da tese na síntese, sem que se possa 'medir' a priori os golpes como em um ringue convencionalmente regulado. Que isso ocorra de fato, de resto, é uma questão de 'política' imediata, já que, na história real, o processo dialético se fragmenta em inúmeros momentos parciais. (GRAMSCl, 1999, P. 292).

Essa dupla perspectiva pode aprofundar o tensionamento para evitar que a RSB se confine a uma reforma parcial de caráter setorial e institucional ou - a pretexto de um realismo político, traduzido em pragmatismo ou transformismo - aceitar um Sistema Único de Saúde (SUS) pobre para pobres e submetido à lógica do setor privado, tal como foi destacado mediante a metáfora do Minotauro da Saúde (SILVA, 2016). Essas são questões que permanecem em aberto para a análise das perspectivas da RSB. E a estratégia a ser adotada não pode ignorar algumas pistas da obra de Gramsci:

\footnotetext{
Se Mazzini tivesse um programa - isto é, não fosse apenas um político 'iluminado' - e compreendesse o movimento de Cavour, mesmo assim não teria como reverter o Risorgimento em um processo jacobino nacional-popular. Mas poderia ter impresso - parece sugerir Gramsci - uma outra dinâmica ao binômio clássico ao transformismo, em que a 'mudança' viesse a preponderar sobre a 'conservação'. (VIANNA, 2004, P. 105).
}

Essa outra dinâmica pode ser uma opção do movimento sanitário enquanto a 'classe ausente' (SANTOS, 2014) permanecer omissa, a democracia for condenada a ser um fetiche 
(DANTAS, 2014) e o socialismo uma utopia.

Entretanto, a hegemonia, enquanto estratégia socialista, vem desde Gramsci sendo colocada como um dos significados da democracia, realista e concreto. $\mathrm{E}$ a radicalização da democracia (LACLAU; MOUFFE, 2010) não soa estranha na construção dessa hegemonia:

Gramsci não deseja um falso igualitarismo, mas luta para que a democracia não seja mais despedaçada pela corrupção, pela exploração e pela opressão. Em seu diálogo consigo próprio e com os outros, chegou à conclusão de que a via democrática é a justa, mas que são enormes as dificuldades a serem superadas e que o desenvolvimento histórico, no âmbito da forma democrática de vida, exige uma disponibilidade de energias morais e intelectuais, para que a 'filosofia da práxis' não se reduza a pragmatismo utilitarista. (BADALONI, 1988, P. 23-24).

Tal alerta parece muito caro ao caso brasileiro desde a transição democrática e, muito especialmente, nos períodos de governo Lula e Dilma. Daí as tarefas urgentes do presente, relativas ao estudo: investigação e constituição de sujeitos da antítese, sobretudo a partir das manifestações de junho de 2013 e dos retrocessos impostos pelo golpe de 2016 .

Portanto, a constituição de sujeitos sociais, individuais e coletivos (TESTA, 2007) pode conceber sujeitos da antítese para aprofundar o processo da RSB na direção da radicalização da democracia, enquanto estratégia para a hegemonia socialista (LACLAU; MOUFFE, 2010). Não sendo ainda possível identificar tais sujeitos na realidade, caberia investir na formação de sujeitos da práxis para sustentarem o processo da RSB e defenderem o direito universal à saúde e o SUS.

Essas questões permanecem em aberto para a análise das perspectivas da RSB, pois a constituição de sujeitos implica um complexo processo de aprendizagem que envolve a autoformação e a transformação dos indivíduos (DALLMAYR, 2001). Entretanto, para além da pedagogia, os sujeitos se constituem através da ideologia, do trabalho e das lutas.

Presentemente, diante da negligência de partidos políticos de esquerda com a formação dos seus militantes, diversos sujeitos são constituídos pela via dos movimentos sociais. Esses, porém, não são virtuosos em si mesmos. Há movimentos sociais progressistas, caracterizados por fazeres propositivos e comprometidos com a emancipação dos sujeitos, a transformação da sociedade, a afirmação de direitos sociais e a defesa das liberdades. E, também, existem movimentos sociais conservadores quando se verifica a imposição de interesses particulares, contrários à emancipação (GOHN, 2003). Os desdobramentos regressivos das Jornadas de Junho nos anos seguintes (MAGNO, 2015), incluindo os vinculados ao golpe de 2016 (TEIXEIRA, 2016), reforçam a distinção elaborada pela autora.

Os movimentos sociais em saúde, como o da Reforma Sanitária, expressam-se mediante a atuação de Conselhos de Saúde e organizações como o Centro Brasileiro de Estudos de Saúde (Cebes), a Associação Brasileira de Saúde Coletiva (Abrasco), a Associação Brasileira de Economia da Saúde (ABrES), a Rede Unida, Fóruns, entre outros. Eles têm sido considerados progressistas, ainda que careçam de uma teoria do sujeito (DALLMAYR, 2001), para melhor entender seus limites e possibilidades.

Essa necessária teoria do sujeito pode tomar como contribuição o pensamento estratégico em saúde (TESTA, 1995) e as pistas teóricas sobre a práxis (VÁZQUEZ, 2007) e o 'portador da antítese' (VIANNA, 2004). O trabalho teórico para a elaboração do conceito de sujeito da antítese segue, portanto, nessa direção. Do mesmo modo, a atenção especial para a pluralidade de vozes em sociedades democráticas, ressaltada por Laclau e Mouffe (2010), estimula investigar, concretamente, a possível existência de sujeitos da antítese. Eles podem emergir dos movimentos sociais vinculados às lutas contra o sexismo, o racismo, a discriminação sexual e a defesa do ambiente, entre outras. 
Tais movimentos, sem abrir mão das suas pautas específicas, apresentam a potencialidade de associarem-se às lutas de classes dos trabalhadores num projeto articulado contra-hegemônico. Cabe, portanto, a identificação de distintos antagonismos na sociedade contemporânea, estabelecendo-se uma cadeia de equivalências entre as diversas lutas contra as distintas formas de subordinação presentes nas relações sociais (LACLAU; MOUFFE, 2010).

Trata-se nesse processo de constituir sujeitos da práxis (individuais e coletivos), que questionem a não garantia do direito à saúde, as iniquidades e as relações de subordinação. Mas a finalidade desse processo de constituição de sujeitos é alcançar sujeitos da antítese capazes de identificar antagonismos sociais para desencadear ação política: "O antagonismo é, portanto, a parteira do sujeito, pois só pode emergir pela subversão da posição subordinada do sujeito" (FLEURY, 2009, P. 39).

\section{Análise de conjuntura e práxis}

A análise de conjuntura supõe a análise de relações de força, examinando um feixe de relações contraditórias, e visa ao conhecimento do desenvolvimento desigual dessas relações em cada um dos níveis que articuladamente compõem a totalidade social (GRAMSCI, 1976). Significa identificar as contradições resultantes do processo de acumulação capitalista e da atuação do Estado, as suas mediações com as condições e as práticas de saúde referentes às diferentes classes e grupos sociais, bem como os enfrentamentos que se dão no âmbito da sociedade e que impõem a ação reguladora, democrática ou coercitiva do Estado.

Considerando a RSB como um processo aberto (AGGIO, 1998), análises de conjunturas poderiam apontar as posições dos sujeitos e a correlação de forças que imprimiriam mudanças ou restaurações no âmbito da saúde.
É justamente o entendimento da RSB para além de uma proposta ou um projeto, mas como um processo, que permite analisar os diversos momentos parciais e a atuação dos sujeitos da práxis, seja conservando algo na síntese, seja reforçando a antítese, enquanto sujeitos da antítese, e alterando o sentido da conservação.

O elemento jacobino passível de ser identificado nesse processo poderia investir, presentemente, na defesa e no aprofundamento da democracia, contribuindo para a alteração da correlação de forças observada nesse estado de exceção que se vai configurando com a chamada Operação Lava Jato e com as ações dos protagonistas do golpe de 31 de agosto de 2016. Os sujeitos da antítese estariam voltados para desequilibrar o binômio conservação-mudança, conferindo um caráter mais progressista para a revolução passiva na RSB. Desse modo, a compreensão mais nítida da revolução passiva, no caso da sociedade brasileira, particularmente, diante de um fenômeno sócio-histórico como o da RSB, pode indicar um critério para a práxis de novos sujeitos sociais constituídos no sentido de mudarem, também, a direção do transformismo.

$\mathrm{O}$ artigo escrito antes da revolta popular, que, no ano de 2013, mobilizou mais de 2 milhões de pessoas, em 438 municípios, defendia a revitalização da sociedade civil no sentido de desequilibrar o binômio da conservação-mudança, ressaltando a força da antítese que poderia emergir dos movimentos sociais (PAIM, 2013A). Apesar das distintas leituras feitas com relação às manifestações de junho de 2013, cumpre reconhecer que a reiteração de direitos assegurados pela Constituição (educação, saúde e participação cidadã) e a extensão de outros (transporte gratuito, saneamento e ética na política e na gestão da coisa pública) eram destacadas na oportunidade e correspondem a direitos e princípios que constavam nos projetos políticos Esperança e Mudança e Democráticopopular, definidos na transição democrática 
(PAIM, 2013A). Entretanto, esses direitos sociais e políticos encontram-se ameaçados e subvertidos pela coalizão de forças retrógradas que tramaram e executaram o golpe de 2016.

Contudo, a consolidação de uma política democrática não pode ser feita apenas pelo Estado, nem por partidos formalizados, cabendo recuperar a análise das classes sociais para explicar a ideologia e a práxis de novas classes trabalhadoras na estrutura social brasileira (ALMEIDA, 2013). A revitalização da sociedade civil, onde se originaram a RSB e o SUS, estimula visitar criticamente o próprio marxismo que lhes fundamentou:

O marxismo clássico trabalhava com um socialismo voltado para a economia. O marxismo soviético com um socialismo voltado para o Estado, e hoje, finalmente, devemos trabaIhar para um socialismo voltado para a sociedade [...]: 'resgatar o social no social-ismo'. (BURAWOY, 2015, P. 60, GRIFO NOSSO).

Esse olhar aguçado para o social, independentemente da presença de utopias, pode orientar o que fazer numa conjuntura tão complexa quanto a atual. Retomando Gramsci, que bem analisou a natureza do Estado moderno e elaborou o conceito de Estado ampliado, podem ser visualizados elementos capazes de revigorar esse socialismo democrático voltado para a sociedade:

Gramsci [...] quer transferir o fruto de seu aprendizado para o 'seu' ator: a sociedade civil, lugar efetivo em que se garante a dominação exercida sobre ele, deve ser, por isso mesmo, o lugar de sua emancipação. O social, como instância prisioneira da sociedade civi burguesa, não tem outro recurso que o da política - uma política que seja a tradução da sociabilidade emergente, e não a política ilusória de mudanças 'por cima', impostas em uma 'pedagogia' da coerção. (VIANNA, 2004, P. 88).

Nessa perspectiva, cabe retomar a centralidade da crítica e da práxis. A construção do SUS público, gratuito e de qualidade passa pela radicalização da Reforma Sanitária e da democracia. Diante de um fenômeno sócio-histórico como a RSB e de uma totalidade concreta e complexa como o SUS, faz-se necessário acionar teorias potentes que ajudem a desvendar o que não se encontra nas aparências. A vitalidade do 'processo' da RSB cria, portanto, espaços virtuais para a constituição de sujeitos da antítese que podem se tornar espaços reais pela via da práxis.

\section{Comentários finais}

Neste ensaio, foram discutidos os conceitos de sujeitos da antítese e sujeitos da práxis na perspectiva da realização de análise de conjunturas e da práxis da Reforma Sanitária. Cabe lembrar que o conceito de sujeito da antítese está baseado na noção de 'portadores da antítese', concebida por Vianna (2004). Não representa um grupo social que se opõe à reforma sanitária, ao contrário, supõe um sujeito social que possa contribuir no sentido de fazer avançar o processo da RSB para além do status quo ou da revolução passiva que marca a história do Brasil.

O presente estudo procurou argumentar que a radicalização da RSB, assim como a luta pela consolidação do SUS democrático, implica a constituição de novos sujeitos e atores sociais para a sua sustentabilidade, recorrendo à práxis e à dialética (sujeitos da práxis). Esses processos poderão favorecer a constituição de sujeitos capazes de desequilibrar o binômio da 'conservação-mudança' da revolução passiva brasileira (sujeitos da antítese). Se a investigação e a práxis ainda não forem capazes de apontar a existência desse sujeito na realidade concreta, caberia continuar apostando na formação dos sujeitos da práxis.

Na conjuntura atual, é possível considerar que esses sujeitos transitem em pelo menos 
três projetos em disputa na saúde: o mercantilista ou expansionista, o revisionista ou racionalizador e o da RSB (PAIM, 2008A).

$\mathrm{O}$ primeiro parece assimilar sujeitos originalmente identificados com o movimento sanitário, mas que, através do transformismo ou do pragmatismo político, têm permitido a privatização da saúde por fora e por dentro do SUS, por meio da expansão dos planos de saúde e da adoção de Organizações Sociais (OS), parcerias público-privadas, terceirizações etc. Esse projeto mercantilista já dispõe dos seus sujeitos organicamente vinculados ao capital, além de outros advindos do movimento sanitário pela via da cooptação, do oportunismo ou do transformismo. Além de possuir sujeitos bem formados ideologicamente, conta com a colaboração dos aparelhos de hegemonia, seja na mídia, nas entidades de saúde e nas universidades.

O projeto racionalizador, cujos conteúdos podiam ser constatados desde a década de oitenta (BAPTISTA, 1997), foi se fortalecendo com a implantação do SUS, sendo exercitado por segmentos anteriormente comprometidos com a RSB, mas que flexibilizam princípios e diretrizes em função dos imperativos da ordem econômica e dos interesses do Estado e das classes hegemônicas. Esse projeto revisionista pode se beneficiar da constituição de sujeitos da práxis, especialmente, funcionários de governo (TESTA, 2007) que passaram pelo desenvolvimento de uma aptidão crítica. Estes podem ser parceiros de sujeitos transformadores ou, na dependência de situações concretas, transformar-se em 'sujeitos da resistência' contra o projeto mercantilista e contra a destruição do SUS, implementado, sobretudo, pelo golpe parlamentar-midiático de 2016.

Já o projeto da RSB toma como referência o pensamento e a práxis do movimento sanitário através do Cebes e de seus parceiros, exigindo a constituição permanente de novos sujeitos sociais, sejam sujeitos da práxis ou sujeitos da antítese. Esse projeto democrático necessita, além de sujeitos da práxis, da constituição de sujeitos da antítese, seja para tornar a revolução passiva à brasileira menos conservadora, seja para tensionar o processo da RSB no sentido de ultrapassar a práxis de reforma parcial, apelando para outros tipos de práxis.

Por conseguinte, os limites e as possibilidades para o desenvolvimento da RSB e do SUS encontram-se condicionados e determinados pelas suas bases de sustentação política, conforme apontam as análises de conjuntura (MAGNO, 2015). Não obstante a derrota dos projetos Esperança e Mudança e o Democrático-popular na conjuntura pós-constituinte (PAIM, 2013A), o minimalismo do Governo Dilma na saúde, as respostas diversionistas do Estado ao povo nas ruas, em 2013, e a ofensiva da direita desde as eleições de 2014 (BAHIA; SCHEFFER, [2014?]; COSTA, 2013; MAGNO, 2015; SCHEFFER, 2015; TEIXEIRA, 2016), a RSB está aí: Eppur si muove (PAIM, 2013B).

Portanto, não houve estagnação do 'processo' da RSB, apesar dos constrangimentos produzidos externa e internamente (fora ou dentro do setor saúde). Mesmo que não tenha cumprido integralmente suas promessas, a RSB persiste enquanto 'processo', com avanços e recuos, idas e vindas, conquistas e retrocessos. Nesse contexto, integrantes do movimento sanitário poderiam se constituir como 'sujeitos da antítese' e, ainda que neutralizados politicamente pela força dos dominantes, não estariam condenados à imobilização nem à inércia ou à resignação.

Estudo anterior apontava para o refluxo dos movimentos sociais e para a redução da presença do Cebes na cena política durante a década de noventa, com maior protagonismo da representação de gestores (Conselho Nacional de Secretários de Saúde - Conass; e Conselho Nacional de Secretarias Municipais de Saúde - Conasems), mas indicava uma retomada do movimento sanitário a partir de 2005 (PAIM, 2008B). Se, antes, o movimento sanitário restringia-se a ações esporádicas e inorgânicas, enquanto os fatos comandavam o processo, reduzindo a força da antítese, a refundação do Cebes, em 2006, 
e a sua atuação político-ideológica posterior poderiam sugerir outros 'sujeitos da práxis', bem como a instauração de novos diálogos entre tais sujeitos e, eventualmente, a constituição de possíveis 'sujeitos da antítese'.

O fato de a RSB se apresentar até o presente como uma 'reforma parcial' não anula as possibilidades de os sujeitos da antítese empurrarem o seu processo para uma 'reforma geral' ou para uma 'revolução no modo de' vida (HELLER, 1986), mediante uma práxis criadora, uma práxis reflexiva e uma práxis política. Tais possíveis históricos, entretanto, nem a 'filosofia da práxis' é capaz de prever:

é possível prever 'cientificamente' apenas a luta, mas não os momentos concretos dela, que não podem deixar de ser resultados de forças contrastantes em contínuo movimento. (GRAMSCI, 1999, P. 121)

\section{Referências}

AGGIO, A. A revolução passiva como hipótese interpretativa da história política latino-americana. In: AGGIO, A. Gramsci, a vitalidade de um pensamento. São Paulo: Unesp, 1998. p. 161-176.

ALMEIDA, C. M. Os 25 anos do SUS: desencanto ou oportunidade. Cadernos de Saúde Pública, Rio de Janeiro, v. 29, n. 10, p. 1944-1946, out. 2013. Disponível em: <http://www.scielosp.org/scielo.php?script=sci_ arttext\&pid=S0102-311X2013001400008 $>$. Acesso em: 2 fev. 2017.

ALTHUSSER, L. Sobre o Trabalho Teórico. Lisboa: Presença, 1978.

BADALONI, N. Gramsci, para além de sua época e de seu país. In: COUTINHO, C. N.; NOGUEIRA M. A.

(Org.). Gramsci e a América Latina. Rio de Janeiro: Paz e Terra, 1988. p. 11-24.

BAHIA, L.; SCHEFFER, M. A saúde nos programas de governo dos candidatos a Presidente da República do Brasil nas eleições de 2014: notas preliminares para o debate. Rio de Janeiro: Abrasco, [2014]. Disponível em: <http://cebes.org.br/site/wp-content/
uploads/2014/07/proposta-sa\%C3\%BAde-presidenciaves-2014.pdf>. Acesso em: 31 jul. 2014.

BAPTISTA, T. W. F. Caminhos e percalços da política de saúde no Brasil: vinte anos da Reforma Sanitária. Brasília, DF: Ministério da Saúde, 1997.

BURAWOY, M. Entrevista Michael Burawoy. Revista Cult, São Paulo, v. 139, p. 60-62, fev. 2015.

BORNHEIM, G. A. Dialética: teoria, práxis; Ensaio para uma crítica da fundamentação ontológica da Dialética. São Paulo: USP, 1983.

COSTA, A. M. Onde foi parar o sonho do SUS? Le Monde Diplomatique Brasil, Santana de Parnaíba, v. 69, p. 30-31, 2013. Disponível em: <http://diplomatique. org.br/onde-foi-parar-o-sonho-do-sus/>. Acesso em: 2 fev. 2017.

DALLMAYR, F. Para além da democracia fugidia: algumas reflexões modernas e pós-modernas. In: SOUZA, J. (Org.). Democracia hoje: Novos desafios para a teoria democrática contemporânea. Brasília, DF: UnB; 2001. p. 11-38. 
DANTAS, A. V. Do socialismo à democracia: dilemas da classe trabalhadora no Brasil recente e o lugar da Reforma Sanitária Brasileira. 2014. 378 f. Tese (Doutorado) - Universidade Federal do Rio de Janeiro, Rio de Janeiro, 2014.

FLEURY, S. Democracia e socialismo: o lugar do sujeito. In: FLEURY, S.; LOBATO, L. V. C. (Org.). Participação Democracia e Saúde. Rio de Janeiro: Cebes, 2009. p. 24-46.

GOHN, M. G. (Org.). Movimentos sociais no início do século XXI: antigos e novos atores sociais. Petrópolis: Vozes, 2003.

GRAMSCI, A. Cadernos do cárcere. Rio de Janeiro: Civilização Brasileira, 1999. v.1.

Concepção dialética da história. Rio de Janeiro: Civilização Brasileira, 1966.

Maquiavel, a política e o Estado moderno. Rio de Janeiro: Civilização Brasileira, 1976.

HELLER, A. Teoría de las necesidades en Marx.

Barcelona: Península, 1986.

IANNI, O. Pensamento social no Brasil. Bauru: Edusc, 2004.

LACLAU, E.; MOUFFE, C. Hegemonia y estrategia socialista: Hacia una radicalización de la democracia. 3. ed. Buenos Aires: Fondo de Cultura Económica, 2010.

MAGNO, L. D. Dos clamores das ruas aos rumores no Congresso: uma análise da conjuntura recente da saúde no Brasil. 2015. 106 f. Dissertação (Mestrado em Saúde Comunitária) - Programa de Pós-graduação do Instituto de Saúde Coletiva, Universidade Federal da Bahia, Salvador, 2015.

PAIM, J. S. A Constituição Cidadã e os 25 anos do Sistema Único de Saúde (SUS). Cadernos de Saúde Pública, Rio de Janeiro, v. 29, n. 10, p. 1927-1936, 2013 a. Reforma Sanitária Brasileira: avanços, limites e perspectivas. In: MATTA, G. C.; LIMA, J. C. F. (Org.).
Estado, Sociedade e Formação Profissional em Saúde: contradições e desafios em 20 anos de SUS. Rio de Janeiro: Fiocruz, 2008a, p. 91-122.

Reforma Sanitária Brasileira: contribuição para a compreensão e crítica. Salvador: Edufba; Rio de Janeiro: Fiocruz; 2008b.

. Reforma Sanitária Brasileira: eppur si muove.

Cadernos de Saúde Pública, Rio de Janeiro, v. 29, n. 10, p. 1952-1953, 2013b.

SANTOS, R. T. O fantasma da classe ausente: as tradições corporativas do sindicalismo e a crise de legitimação do SUS. 2014. 170 f. Tese (Doutorado em Ciência Política) - Faculdade de Filosofia e Ciências Humanas, Universidade Federal de Minas Gerais, Belo Horizonte, 2014. $170 \mathrm{p}$.

SCHEFFER, M. O capital estrangeiro e a privatização do sistema de saúde brasileiro. Cadernos de Saúde Pública, Rio de Janeiro, v. 31, n. 4, p. 663-666, 2015. Disponível em: <http://www.scielosp.org/pdf/csp/ v31n4/0102-311X-csp-31-04-00663.pdf >. Acesso em: 2 fev. 2017.

SCHRAIBER, L. B. Saúde Coletiva: um campo vivo. In: PAIM, J. S. Reforma Sanitária Brasileira: contribuição para a compreensão e crítica. Salvador: Edufba; Rio de Janeiro: Fiocruz, 2008.

SILVA, T. H. S. Força ou Consenso: a Reforma Sanitária Brasileira entre o Dilema Reformista e o Minotauro da Saúde. 2016. 193 f. Dissertação (Mestrado) - Faculdade de Saúde Pública, Universidade de São Paulo, São Paulo, 2016.

TEIXEIRA, C. F. A saúde no Brasil em 2016 através das lentes do OAPS. Observatório de Análise Política em Saúde, [2016]. Disponível em: <http://analisepoliticaemsaude.org/oaps/documentos/pensamentos/14823366 08585aa9600982e.pdf>. Acesso em: 2 fev. 2017.

TEIXEIRA, S. M. F. (Org.). Reforma Sanitária em busca de uma teoria. São Paulo: Cortez; Rio de Janeiro: Abrasco, 1989. 
TESTA, M. Decidir en Salud: ¿Quén?, ¿Cómo? Y

¿Porqué? Salud Colectiva, Buenos Aires, v. 3, n. 3, p. 247-257, set./dez. 2007. Disponível em: <http:// www.scielo.org.ar/scielo.php?script=sci_arttext\&pid =S1851-82652007000300003 >. Acesso em: 2 fev. 2017 .

Pensamento Estratégico e Lógica de

Programação: o caso da saúde. São Paulo: Hucitec; Rio de Janeiro: Abrasco, 1995.

VÁZQUEZ, A. S. Filosofia da práxis. Buenos Aires:
Consejo Latinoamericano de Ciencias Sociales; São Paulo: Expressão Popular, 2007.

VIANNA, L. W. A revolução passiva: iberismo e americanismo no Brasil. 2. ed. rev. ampl. Rio de Janeiro: Revan, 2004.

Recebido para publicação em março de 2017

Versão final em julho de 2017

Conflito de interesses: inexistente

Suporte financeiro: não houve 